\title{
COVID-19 pandemic: vaccine and new monoclonal antibodies, point of view
}

\author{
Antonio Vitiello ${ }^{1} \cdot$ Raffaele La Porta $^{2} \cdot$ Laura Pianesi $^{3} \cdot$ Francesco Ferrara $^{4}$ (i)
}

Received: 17 February 2021 / Accepted: 26 February 2021 / Published online: 12 March 2021

(c) Royal Academy of Medicine in Ireland 2021

\section{Dear Editor,}

The COVID-19 pandemic is the most serious health emergency of the twenty-first century, to date causing approximately 106 million people to be infected and 2.32 million deaths worldwide [1]. Despite the strict measures conducted in all countries, the pandemic seems not to stop, causing health, economic, and social problems [2,3]. Recently, some SARS-CoV-2 variants of potential concern have been highlighted, such as VOC 202012/01 discovered in the UK, the 501.V2 variant identified in South Africa, and the variant known as P.1 identified in Brazil [4]. A few months ago, the first COVID-19 vaccines were authorized. Mass vaccination seems to be the winning way to defeat the pandemic; however, the interest of the scientific world must continue in the search for therapeutic agents able to reduce the severity of the disease and avoid death in case of contagion. Recently, the first monoclonal antibodies against SARS-CoV-2 have been authorized. Experimental therapeutic treatments used so far for the management of COVID19-positive patients have been mostly directed to avoid serious complications of the infection, anti-inflammatory drugs, antivirals [5, 6], and anticoagulants [7, 8]; how-

Francesco Ferrara

francesco.ferrara@uslumbria1.it

Antonio Vitiello

antonio.vitiello2@uslumbria1.it

Raffaele La Porta

raffaele.laporta@sanita.marche.it

Laura Pianesi

laura.pianesi@uslumbria2.it

1 Pharmaceutical Department Usl Umbria 1, Perugia, Italy

2 Pathology Department ASUR Marche, Area Vasta 1, Urbino, Italy

3 Pharmaceutical Department Usl Umbria 2, Foligno, Italy

4 Pharmaceutical Department Usl Umbria 1, A.Migliorati street, Perugia 06132, Italy ever, only a massive and important mass vaccination in all countries could be necessary to stop the wave of the pandemic. Vaccines available on the market and those under testing show good efficacy and safety $[9,10]$. But are they equally effective against the newly identified variants? We believe that COVID-19 vaccines are likely to show good efficacy against these newly identified viral variants as well. This is for several reasons, in the "English variant," some mutations have been identified involving the "spike protein," the target of the antibodies developed by the main vaccines, but the spike protein is a molecule composed of about 1200 amino acids and the immune system produces dozens of antibodies directed against various parts of this protein [4]. The mutations identified could make one or a few of these antibodies useless, but there would still be dozens of antibodies capable of recognizing the spike protein. Experience with vaccines against influenza viruses suggests that to escape the immune response, viruses must acquire hundreds of mutations, this can only happen over a long period. Probably to date, it is not the genetic mutations of the virus that determine the severity of the disease, but rather some human genetic variants that may make some patients more susceptible to severe forms of COVID-19. Recently, first monoclonal antibodies against SARS-CoV-2 have been authorized [11], but some issues remain to be clarified for the use. Specifically, who can undergo treatment with monoclonal antibodies? Currently, monoclonal antibodies are intended only for patients with newly diagnosed COVID-19 who are not sick enough to be in the hospital, but who have certain risk factors for severe infection. The target population that may benefit has yet to be fully and clearly identified. Also, another aspect to consider, can some SARS-CoV-2 mutations cause changes in the spike protein that could interfere with the efficacy of currently available monoclonal antibodies? To date, we believe that vaccines and monoclonal antibodies are valid therapeutic weapons to stop the global COVID-19 pandemic; however, additional clinical evidence is urgently needed. 


\section{References}

1. World health organization (WHO) (2021) Situation Reports February 2021. https://www.who.int/emergencies/diseases/ novelcoronavirus2019/situation-reports

2. Wang C, Horby PW, Hayden FG, Gao GF (2020) A novel coronavirus outbreak of global health concern. Lancet 395(10223):470473. https://doi.org/10.1016/S0140-6736(20)30185-9

3. Zhu N, Zhang D, Wang W et al (2020) China Novel Coronavirus Investigating and Research Team. A novel coronavirus from patients with pneumonia in China, 2019. N Engl J Med 382(8):727-733. https://doi.org/10.1056/NEJMoa2001017

4. WHO(2021). https://www.who.int/csr/don/31-december-2020-sars-cov2variants/en/2020-sars-cov2-variants/en/

5. Ferrara F, Porta R, D'Aiuto V, Vitiello A (2020) Remdesivir and COVID-19. Ir J Med Sci 17:1-2. https://doi.org/10.1007/s11845-02002401-5

6. Vitiello A, Ferrara F (2020) Remdesivir versus ritonavir/lopinavir in COVID-19 patients. Ir J Med Sci 18:1-2. https://doi. org/10.1007/s11845-020-02440-y
7. Vitiello A, La Porta R, Ferrara F (2021) Scientific hypothesis and rational pharmacological for the use of sacubitril/valsartan in cardiac damage caused by COVID-19. Med Hypotheses 147:110486. https://doi.org/10.1016/j.mehy.2021.110486

8. Vitiello A, La Porta R, Ferrara F (2020) Sacubitril, valsartan and SARS-CoV-2. BMJ Evid Based Med 111497. https://doi. org/10.1136/bmjebm-2020-111497

9. Voysey M(2021) Safety and efficacy of the ChAdOx1 $\mathrm{nCoV}-19$ vaccine (AZD1222) against SARS-CoV-2: an interim analysis of four randomised controlled trials in Brazil, South Africa, and the UK. Lancet 397(10269):99-111. https://doi.org/10.1016/S0140-6736(20)32661-1

10. Mercado NB, Zahn R, Wegmann F et al (2020) Single-shot Ad26 vaccine protects against SARS-CoV-2 in rhesus macaques. Nature 586(7830):583-588. https://doi.org/10.1038/s41586-020-2607-z

11. Malani PN, Golub RM (2021) Neutralizing monoclonal antibody for mild to moderate COVID-19. JAMA. https://doi.org/10.1001/ jama.2021.0585

Publisher's Note Springer Nature remains neutral with regard to jurisdictional claims in published maps and institutional affiliations. 